\title{
Strategies for the Discovery and Development of Anti-Diabetic Drugs from the Natural Products of Traditional Medicines
}

\author{
Stanley M.H. Chan and Ji-Ming Ye \\ Molecular Pharmacology for Diabetes Group, Health Innovation Research Institute and School of Health Sciences, \\ RMIT University, Melbourne, VIC, Australia.
}

Received, May 9, 2013; Accepted, May 10, 2013; Published, May 10, 2013.

\begin{abstract}
This review discusses issues largely from the biological point of view about the targeted approaches for the use of natural products for the discovery of anti-diabetic drugs in collaboration with medicinal chemists and computer-aided drug design. A major thrust of this review reflects the collaborative research of four institutions: RMIT University (Australia), Garvan Institute of Medical Research (Australia), Shanghai Institute of Materia Medica of the Chinese Academy of Science (China) and Sun-Yat Sen University (China) in the past eight years. By joining forces of biomedical research in diabetes and medicinal chemistry with a focus on traditional medicine, they are trying to bridge the West (the latest research discoveries in biomedical research) with the East (traditional medicine) to step forward in drug discovery from natural products.
\end{abstract}

This article is open to POST-PUBLICATION REVIEW. Registered readers (see "For Readers") may comment by clicking on ABSTRACT on the issue's contents page.

\section{TYPE 2 DIABETES AND PROBLEMS IN CURRENT TREATMENTS}

Currently, there are 150 million people with diabetes worldwide and this figure is expected to increase to over 300 million by 2025 . This global pandemic is driven by type 2 diabetes (T2D) which accounts for $\sim 90 \%$ of all diabetes. T2D represents a coronary heart disease 'risk equivalent' as atherosclerotic cardiovascular disease is responsible for $80 \%$ of diabetic mortality and more than $75 \%$ of all hospitalisations for diabetic complications (1). The major metabolic defects of T2D are insulin resistance (impaired sensitivity of insulin action in its target tissues: muscle and liver) and the failure of pancreatic beta cells to produce sufficient insulin to compensate for the reduced insulin sensitivity. As insulin resistance usually precedes and contributes to beta cell failure, reversal of insulin resistance is critical for the treatment of T2D. Current therapeutics for treating insulin resistance primarily target two mechanisms: peroxisome proliferator-activated receptors (PPARs) such as thiazolidinediones (TZDs) (2) and AMPK-activated protein kinase (AMPK) such as metformin (3). Indeed these two classes of drugs are the most commonly used medications for the treatment of T2D. However, TZDs can have undesirable side-effects (weight gain, fluid retention and heart failure). Although metformin does not cause weight gain, it mainly acts in liver rather than muscle, thus on its own is not a complete therapy. For these reasons, researchers have undergone a worldwide search of new agents with greater therapeutic efficacy (4).

$\begin{array}{lcrr}\text { NATURAL } & \text { PRODUCTS } & \text { AS } & \text { AN } \\ \text { IMPORTANT } & \text { SOURCE } & \text { FOR } & \text { DRUG } \\ \text { DISCOVERY } & & & \end{array}$

Natural products have a long history of being used as a medication. Although many have been superseded by conventional pharmaceutical approaches, there is currently resurgence in interest in the natural products industry to treat diseases as they have been a fruitful source of drugs. It is estimated that more than $25 \%$ of all current prescription drugs are derived from plants. Among the small-molecule drugs developed over the past 25 years or so, $5 \%$ were natural products, $27 \%$ were derivatives of natural products and $30 \%$ were synthetic drugs inspired by natural products (5). The most successful story of the discovery of the anti-diabetic drugs from natural products is metformin. Its parent compound is the natural guanide originally purified from the plant Goat's Rue (6). Following the discovery of its anti-diabetic effects, guanide was then chemically modified as a biguanide (metformin) to improve efficacy and reduce toxicity.

Corresponding Author: Professor Ji-Ming Ye, PhD, MD; School of Health Sciences, RMIT University; Building 202, Level 4, PO Box 71, Bundoora; Melbourne, Australia; Email: jiming.ye@rmit.edu.au 
Currently, metformin is the most commonly used drug for the treatment of T2D.

As natural products are potential rich sources of chemical diversities for drug discovery, they also pose a number of big challenges to researchers for a number of reasons compared with industry drug discovery from synthetic small molecules. For the chemists, not only the process of purification can be slow and expensive, but also the purified natural product compounds are often difficult to modify and small in quantity. For biomedical researchers (particularly in academic institutions), it is difficult to conduct a large scale of random screenings and tests due to resource constrains.

Traditional medicines (TM) such as Chinese medicines (TCM) have been increasingly regarded as an important source for drug discovery $(7,8)$. Rather than screening for large and complex small molecule libraries of natural products, which incurs great expenses and time as well as eliciting potential toxicity issues, it appears to be expeditious to take a more targeted approach using TCM with known efficacy on metabolic disorders. As TCM has been used for centuries to treat diseases including diabetes researchers can take advantage of the vast literature (including traditional and experimental usage) already available for data mining and perform computer screenings. This approach also overcomes the constraints of limited quantity often encountered in research of other natural products because TCMs are manufactured on a large scale. However, major challenges remain in the identification of active components from TCMs. Many of the claimed efficacies of TCM are not based on robust clinical trials of a modern standard and the mode of action is generally not known. In addition, it is widely believed that the beneficial effects of TCMs are due to combinational effects. This presents significant difficulties in isolating the active components from the natural products in TCM. Therefore, designing manageable screens becomes essential to guide the identification and separation of the active molecules from TCM ingredients.

\section{THE ANTI-DIABETIC NATURAL PRODUCTS FROM TCM}

The current approaches of drug discovery can be broadly divided into two categories: target-based and phenotypic screening. Target-based approach involves screening a single molecular target against hundreds of thousands of small molecules, identifying 'hits' and taking these further through pre-clinical and clinical trials which is also known as the "Bench to Bedside" approach (Figure 1). The advantage of this approach lies in the application of existing molecular and chemical knowledge to investigate specific molecular hypotheses (ie. modulation of a single target), and it is often high-throughput adaptable (9). However, the use of single target based drug screens has an extremely high attrition rate and it is limited by the complexity of diseases (10) such as T2D, which represent defects in multiple organs involving multiple biochemical pathways. Although widely used in the industry for high throughput screening, this type of screen might not be sufficient to capture the pathophysiology of the disease. The fact that there is very little improvement in the approval rate of drugs from synthetic small molecules in the last twenty years despite substantial advances in target identifying technology (eg. RNA interference and X-ray crystallography) reveals the limitation of this approach to drug discovery $(11,12)$.

Phenotypic screenings are cell-based assays which can overcome many of these limitations because they have the potential to select for compounds that modify end-point biological response rather than individual targets per se (13). This is because a small molecule often binds to more than one targetor modifies the activity of regulatory nodes that are dominant control points in the context of the biological system. Therefore, cell-based drug screens have the potential to yield more information about a biological system in part because they can be tailored to screen for complex outcomes such as changes in cell morphology or gene expression (Figure 1). However, cell-based screening of natural products may pose challenges in establishing mechanisms of action, which usually involves identification of the molecular target(s). Compared with the targetbased screening, the phenotypic screening is less high throughput. As phenotypic screening yields higher success rates, we have opted to use this approach to screen the TCM-derived natural products in our research (14-17).

\section{CELL-BASED SCREENINGS}

\section{GLUT4 translocation assay}

This screen measures the movement of the insulin responsive glucose transporter, GLUT4 to the cell surface of insulin responsive target cells (adipocytes and myotubes), which represents a key action of insulin in regulating glucose transport. As insulin responsive glucose transport is defective under the states of insulin resistant and considerable evidence, this may be the most relevant defect giving rise to insulin resistance. 


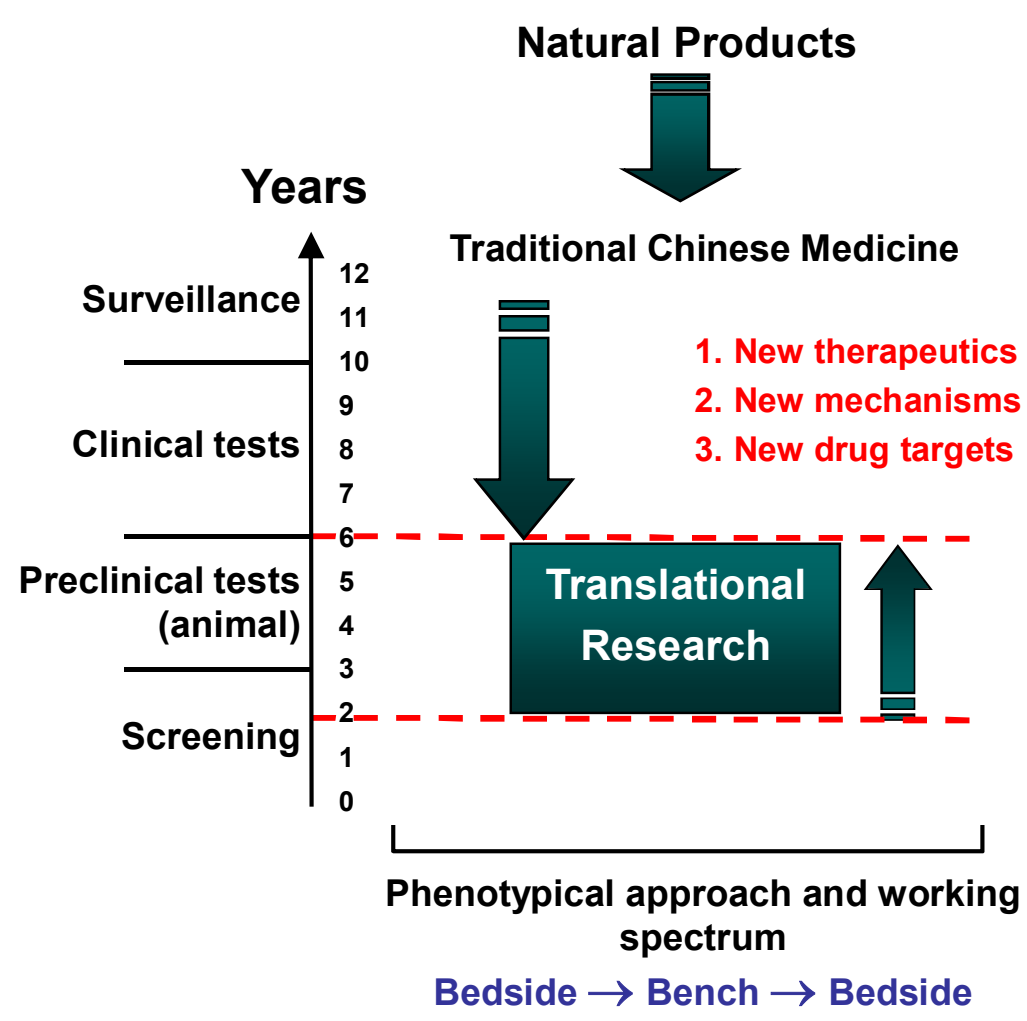

Figure 1. Current approaches for discovery of anti-diabetic drugs from TCMs. The conventional approach of drug discovery relies on intensive screening of a large number of small molecules to gradually narrow down the promising leads to proceed forward to clinical tests. Many of the small molecules that passed the initial screens may fail to pass the stringency of clinical tests, resulting in a high attrition rate. Moreover, the typical time frame for this type of drug discovery proceeding requires a minimum of ten years. In contrast, TCM is one type of natural product which has been extensively used for various clinical conditions such as T2D. Researchers can take advantage of the existing literature for data mining to identify new drug entities and possible mechanism of action to accelerate R \& D process for drug discovery.

Importantly, the insulin dependent movement of GLUT4 is one terminal manifestation of insulin action and its molecular regulation potentially involves the activity of hundreds of different molecules $(18,19)$. The James laboratory at the Garvan Institute has developed a high throughput screening based on the measurement of GLUT4 translocation in both 3T3-L1 preadipocytes and L6 myotubes (18). Using this cell-based assay as a first-line screening, we have screened for the derivatives developed from berberine, a natural product commonly used in TCM, to optimize its anti-diabetic efficacy (14). By using this cellbased assay as a first-line screening, we have successfully isolated active ingredients from bitter melon used in Asia $(15,20,21)$ and identified novel triterpenoids (Figure 2) with anti-diabetic properties $(15,22)$. In muscle cell lines, the GLUT4 translocation assay is generally more sensitive (up to 5-fold; Figure 2) than the measurement of glucose uptake (maximum $\sim 2$ fold). Several other laboratories have also used a GLUT4 translocation assay to screen for antidiabetic compounds (22-24).

From our experience, this assay offers far greater sensitivity and reliability than the glucose uptake assay, which is another commonly used end-point assay for glucose metabolism. Together with its high throughput capacity, this end-point assay is a very useful tool to allow for rapid identification of the potentially efficacious components ("hits") from TCM to be taken forward for further development.

\section{Lipid accumulation assay}

Lipid accumulation within insulin responsive tissues is a key pathophysiology leading to the development of insulin resistance (25). Reducing lipid accumulation in insulin responsive tissues is not only critical for the treatment of T2D but also a feasible strategy for therapeutic development. For this reason, our laboratory has developed a 
high throughput phenotypic screening assay in 3T3-L1 adipocytes (17). This assay measures the cellular triglyceride level as an end-point readout and has the advantage to capture the lipidlowering efficacy of potential candidates at different sites in lipid metabolic pathways (Figure 3). Following validation by a series of biochemical and pharmacological tests, this assay was applied to screen more than 200 candidates selected from different classes of compounds from TCM. With this assay we were able to identify more than 40 potential anti-diabetic compounds and confirmed the in vivo efficacy of two of these newly-identified compounds (oxymatrine and albiflorin) in animal models of diet-induced insulin resistance (17). This hence provides a strong support for the application of this screening assay for the discovery of novel anti-obese and anti-diabetic drugs.

Cell-based insulin resistance models

In addition to screening for lipid-lowering efficacy, cell-based screening can also be

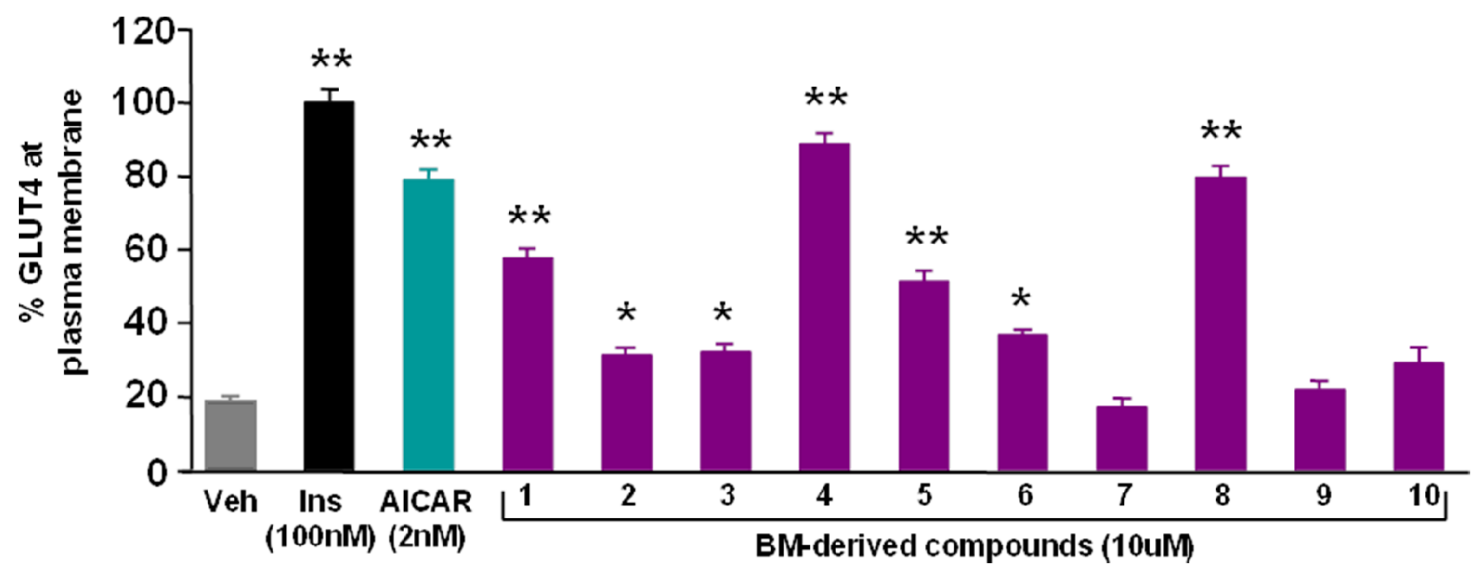

Figure 2. The use of the GLUT4 translocation assay for the identification of new anti-diabetic drugs. L6 myotubes expressing hemagglutinin (HA) tagged GLUT4 were incubated with vehicle (Veh) or $10 \mathrm{mM}$ bitter melon (BM)derived test compounds for $30 \mathrm{~min}$, with $100 \mathrm{nM}$ insulin (Ins) and $2 \mathrm{mM}$ AICAR stimulations serving as a positive control. The result is expressed as a percentage of the maximum effect of insulin $(100 \%)$ in the form of means \pm SE. $* p$ $<0.05, * * \mathrm{p}<0.01$ versus Veh control. Diagram adapted from (15).

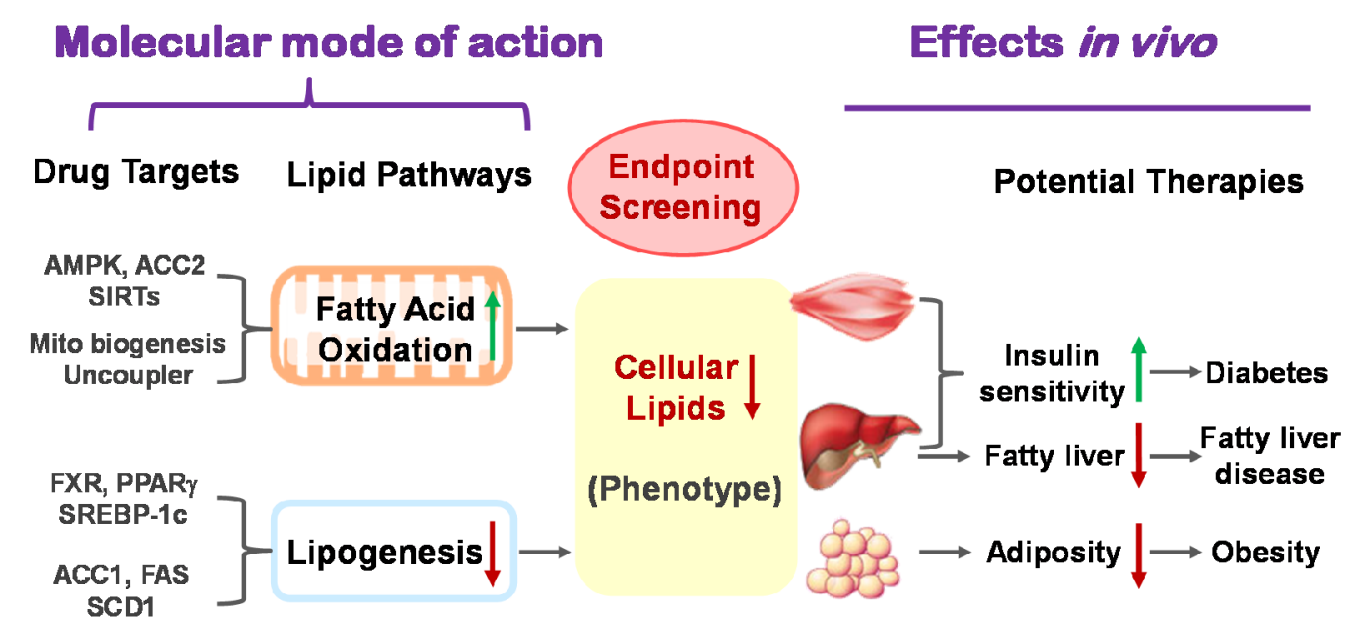

Figure 3. The rationale of screening cellular lipids for the identification of new anti-diabetic drugs. Lipid accumulation seen during obesity is an important driver of insulin resistance and T2D. This phenotypical screen is an endpoint assay designed to capture drugs that act at different targets in the upstream pathways of lipid metabolism leading to a net reduction of cellular lipid content by increasing FA oxidation (energy expenditure) and/or inhibition of the de novo synthesis of lipids. In physiological context, reduction of cellular lipids can improve insulin sensitivity in the liver and muscle, as well as adiposity which are beneficial to T2D. Diagram adopted from (26). 
modified to enable screening of insulin sensitizing properties of the potential TCM candidates. This method utilises the observation that both L6 myotubes or 3T3-L1 adipocytes are responsive to a range of metabolic insults that recapitulate common causes of insulin resistance in mammals, including hyperinsulinemia (via the exposure to chronic insulin), inflammation (elicited by tumor necrosis factor $\alpha$ ), Cushing's syndrome/antiinflammatory steroids (dexamethasone treatment), and hyperlipidemia/dyslipidemia (palmitate incubation), as well as oxidative stress (incubation with glucose oxidase) (27). These insulin resistance models can then be coupled to the cellbased assays such as the GLUT4 translocation assay to achieve high throughput screening and allow for further dissection regarding the mechanism of action of the lead TCM compounds.

\section{Gene signature}

The availability of sequenced genomes and new computational tools has added a new dimension to drug discovery. The use of gene signature profiling has revolutionized multiple areas of the drug discovery including target identification, validation, compound selection, pharmacogenomics, biomarker development, clinical trial evaluation and toxicology. Gene signature is the study/profiling of gene sets that are transcribed or expressed from genomic DNA under a given a biological state of interest. Gene transcription/expression is a major determinant of cellular phenotype and function, and is also responsible for the variation of cellular responses to environmental cues. Hence gene signature can offer much information not only on the function of the gene sets, but the expression magnitude and kinetic can also help researchers to understand the biological roles of the encoded proteins which is useful particularly in chronic diseases like diabetes and cancers $(28,29)$. For example, 2 recent articles published in Science Translational Medicine $(30,31)$ have successfully used this approach to demonstrate potential new therapeutic uses for certain approved drugs. These authors respectively showed that cimetidine (anti-ulcer agent) could be applied to treat lung adenocarcinoma, while topiramate (anticonvulsant) could be a new therapy for inflammatory bowel disease. These findings provide a proof-of-concept for the use of the gene signature as a novel means of drug discovery with relevance to underlying mechanism of action. Given the polygenic nature of diabetes, it is not uncommon for individuals with the same disease to manifest with a different profile of gene signature. The knowledge gained from the profiling could potentially help to personalise therapies to more effectively treat different diabetes-suffering patients, similar to the longstanding "Personalized Medicine Paradigm" in TCM (32).

\section{EVALUATION OF THE IN VIVO EFFICACY}

To evaluate the in vivo efficacy, the most promising small molecules (hits) obtained from the above screenings can then be selected for further studies in animal models to determine the in vivo significance. The in vivo studies in animal models are critical because not all findings in cellbased studies can be translated into the real life situation due to the chemical properties of the test compound. Moreover, the beneficial effects derived from animal models will have more direct implications for the treatment of T2D and other metabolic diseases in humans than that derived from cell models alone. Hence, animal experimentation is proven to be a reliable model for the discovery and validation of new treatments for T2D, and it is often regarded as pre-clinical research. Several well-established animal models of type-2 diabetes are discussed below.

Leptin is the satiety hormone produced by adipocytes. With the identification of leptin being the master regulator of energy intake and energy expenditure (33), Leptin (ob/ob) and its receptor $(\mathrm{db} / \mathrm{db})$ mutation have been a valuable models for therapeutic discovery. Mice homozygous for the leptin mutation (ob/ob) are hyperphagic resulting in weight gain and becoming rapidly obese. These mice are hyperglycemic at a young age. Depending on the background of the mice (34), certain strains such as the C57BLKS/J develops severe hyperglycemia and diabetic conditions with age, while the hyperglycemia is only transient $\mathrm{C} 57 \mathrm{BL} / 6 \mathrm{~J}$ background which is a common strain used in T2D research. Although glycemia may be normal, plasma insulin levels increases steadily in the $\mathrm{C} 57 \mathrm{BL} / 6 \mathrm{~J} \mathrm{ob} / \mathrm{ob}$ mice leading to the manifestation of hyperinsulinemia by $14-16$ weeks of age (33). For these reasons, the $\mathrm{C} 57 \mathrm{BL} / 6 \mathrm{~J}$ background is particularly useful to mimic early stages of type- 2 diabetic conditions, while the C57BLKS/J background is more useful to study the effects of therapeutics on advanced stages of the disease (35). Unlike the ob/ob animals, $\mathrm{db} / \mathrm{db}$ animals harbour mutation of the leptin receptor gene which gives rise to a defect in leptin signalling. The leptin receptor is highly expressed in the hypothalamic region of the brain, and defects in this protein render the animals 
unable to regulate their energy stores appropriately. As a result, the affected animals become hyperinsulinemic very early in life (10-14 days of age), and are obese by the time they are 3 4 weeks old. On the C57BL/6 background, the animals display hyperglycemia and hypertriglyceridemia, and are insulin resistant (36, 37). For this reason, $d b / d b$ animals have been used extensively as a preclinical drug validation model for anti-diabetic drug discovery (38).

The use of these models also has limitations, as leptin or its receptor deficiency presents extreme genetic models of obesity and insulin resistance/diabetes which may not be truly reflecting the pathophysiology of that in human. Moreover, natural mutations of the $\mathrm{OB}$ gene (which encodes for leptin) are rare and do not manifest as a common cause of increased body weight in humans $(39,40)$. For these reasons, our laboratory has employed a murine diabetic model produced by chronic feeding of a high-fat (HF) diet combined with low doses of streptozotocin (STZ; $40 \mathrm{mg} / \mathrm{kg} / \mathrm{day}$ for five consecutive days). Chronic HF feeding in rodents is a widely used model of insulin resistance, which is associated with lipid accumulation in muscle and liver (41, 42). However, HF feeding alone is insufficient to cause diabetes due to the capacity of pancreatic $\beta$ cells to increase insulin secretion to compensate for the insulin resistance (43). As injection of high dosage $(150 \mathrm{mg} / \mathrm{kg})$ of STZ can have severe effects in the pancreas resulting in the ablation of insulin production, we administered multiple low doses of STZ to specifically dampen the ability of pancreatic $\beta$-cells to increase insulin secretion during HF-feeding to generate hyperglycaemia $(26,44)$. The severity of the diabetic phenotype generated using this protocol is less extreme than that of the genetic models and is of much greater relevance to the development of T2D in human (45). Unlike the HF feeding model which glucose tolerance tests are required to monitor the progression of the metabolic phenotype, phenotyping of the HF-STZ mice can be achieved by simpler means such as measuring fasting blood glucose and triglyceride levels from tail sampling, which presents a major advantage and adaptability to high-throughput drug screening.

\section{INVESTIGATION OF THE MOLECULAR MODE OF ACTION}

Once the in vivo efficacy is confirmed, the next step is to understand the molecular mode of action for the identified targets. Insulin resistance is a major metabolic characteristic of type 2 diabetes, hence counteracting insulin resistance holds the key for the therapeutic interventions. There are different types of insulin resistance resulting from different mechanisms which include active intracellular lipids (46), inflammatory cytokines and endoplasmic reticulum (ER) stress (47), and/or mitochondrial oxidative stress (48). Although varying in degrees, all these mechanisms are associated with obesity (45). The use of animal models has the advantage of capturing all of these metabolic features associated with obesity which can offer clues towards the underlying mechanism of action for the identified leads. For example, reduction of body weight gain and fat depots without altering food intake would suggest an increase in energy expenditure. This cause can then be further assessed by indirect calorimetry using metabolic cages, as well as measuring levels of triglyceride and cholesterol in the plasma and metabolicactive tissues. In our experience, alleviation of insulin resistance often results from reduced obesity and/or lipid accumulation in muscle and liver, and that pharmacological treatment to reduce lipids in muscle and liver is often linked to increase expression of genes catalyzing fatty acid oxidation namely AMPK, PCG-1 $\alpha$, UCP2 and/or UCP3. The data from the animal experimentations can then help to design specific molecular interventions in vitro to pin point the cellular target. Using this approach, we have demonstrated the anti-diabetic activity of the novel bitter melon-derived triterpenoids is attributable to its ability to increase the activity of 5' AMP-activated protein kinase (AMPK), which is a key protein responsible for energy metabolism (15).

\section{CLOSING REMARKS}

In collaboration with the Shanghai Institute of Materia Medica (SIMM) and Sun-Yat Sen University, we have now established a library of diverse small molecules from a range of TCMs with potential efficacy using various cell-based assays, including an innovative and proprietary GLUT4 translocation assay that reconstitutes one of insulin's most critical actions - the insulinregulated movement of the GLUT4 glucose transporter to the plasma membrane. This process facilitates insulin-dependent entry of glucose into muscle and fat after a meal and is one of the major mechanisms underpinning insulin resistance (18). Based on the GLUT4 translocation assay we have identified berberine (BBR) (50), BBR derivatives with substantially improved in vivo efficacy (14) and novel triterpenoids from the vegetable bitter melon 


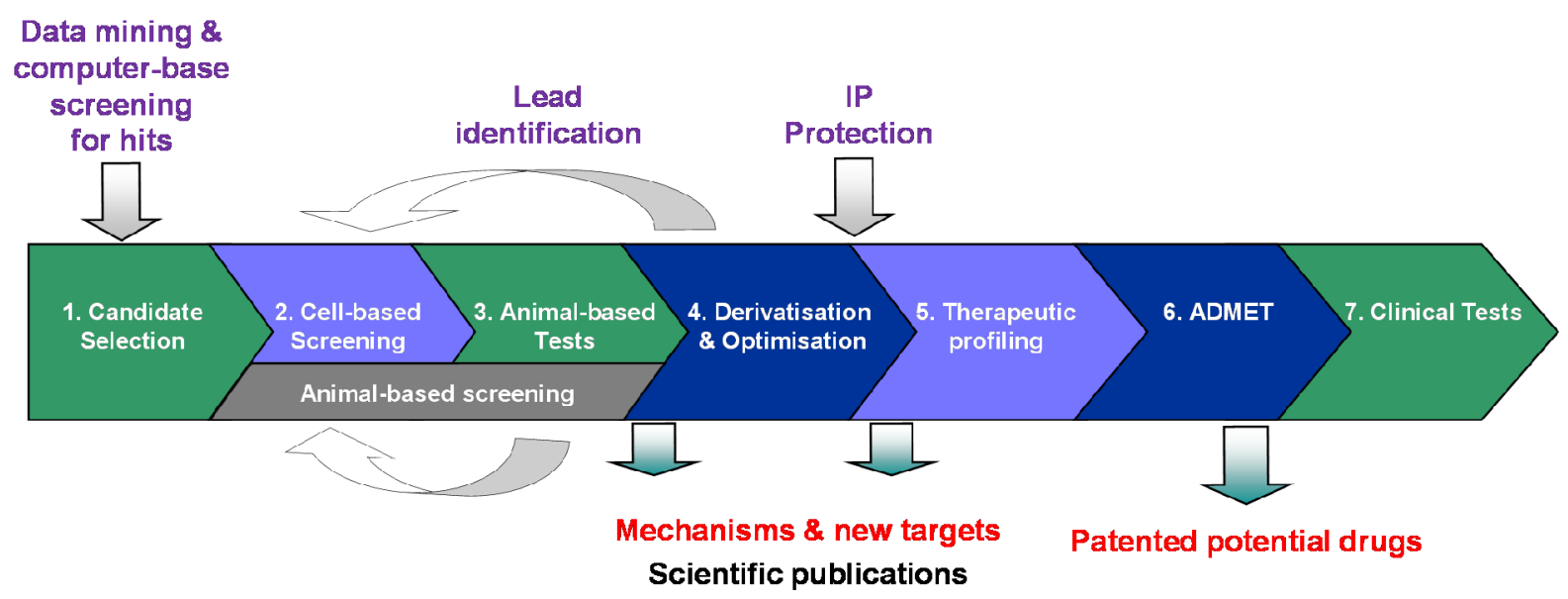

Figure 4. Schematic flow of drug discovery from TCM-derived natural products. Prior to cell based-screening, data mining of the existing literature and computer-based virtual screenings are performed to analyze active chemicals/ingredients of TCMs for candidate selection. Candidate compounds that demonstrated effectiveness in the cell-based screening will then be taken forward to animal experimentation (often in mice). Alternatively, animal-based screening can be applied if sufficient quantity of the purified compound is available. Animal experimentations in turn will provide valuable information to allow for the design of derivatives of the lead compounds with improve drug properties, as well as protocol optimization if necessary. These derivatives are subjected to another round of screening and animal experimentations, the promising lead(s) can then be patented and proceed to therapeutic profiling and clinical tests. Meanwhile, the obtained knowledge on the mechanism of action and target of the lead compounds can result in scientific publications.

(BM) $(15,22)$ which activates the AMPK pathway via alternative mechanisms. Using the approach illustrated in Figure 3, we have also conducted cell-based screens on $\sim 500$ compounds selected from two large banks of different classes of TCM-derived small molecules. This has yielded a number of small molecules with promising efficacy in reversing insulin resistance with well-defined modes of action. These findings have resulted in four patent applications and considerable attention from the media and the pharmaceutical industry. However, the primary cellular targets linking to these pathways are unknown largely due to the limitation of the current methods available for use. This is now a crucial point for us to identify their biological targets to advance our understanding of the molecular mechanisms for the metabolic effects of these small molecules leading to the reversal of insulin resistance. We believe that the research outcome will be very significant and highly relevant to public health and the treatment of diabetes.

\section{ACKNOWLEDGEMENTS}

We would like to acknowledge the contribution to the collaborative work from Dr David James, Dr Edward Kraegen and Dr Nigel Turner (Garvan
Institute of Medical Research, Australia), Dr Jia $\mathrm{Li}$, Dr Yang Ye and Dr Lihong Hu (Shanghai Institute of Materia Medica, China), Dr Jun Xu (Sun-Yat Sen University, China), Mr Xiaoyi Zeng and Ms Xiu Zhou (RMIT University, Australia). This review is supported by National Health and Medical Research Council Program Grant 535921 (allocation to JMY) and Australian Research Council Discovery Grant (PD11010296 to JMY).

\section{REFERENCES}

1. Zimmet P, Alberti KG, Shaw J. Global and societal implications of the diabetes epidemic. Nature. 2001;414(6865):782-7.

2. Moller DE. New drug targets for type 2 diabetes and the metabolic syndrome. Nature. 2001 Dec 13;414(6865):821-7. PubMed PMID: 11742415. Epub 2001/12/14. eng.

3. Bruce CR, Hoy AJ, Turner N, Watt MJ, Allen TL, Carpenter $\mathrm{K}$, et al. Overexpression of carnitine palmitoyltransferase-1 in skeletal muscle is sufficient to enhance fatty acid oxidation and improve high-fat diet-induced insulin resistance. Diabetes. 2009 Mar;58(3):550-8. PubMed PMID: 19073774. Pubmed Central PMCID: 2646053.

4. Smyth S, Heron A. Diabetes and obesity: the twin epidemics. Nat Med. 2006 Jan;12(1):75-80. PubMed PMID: 16397575.

5. Schmidt BM, Ribnicky DM, Lipsky PE, Raskin I. Revisiting the ancient concept of botanical 
therapeutics. Nat Chem Biol. 2007 Jul;3(7):360-6. PubMed PMID: 17576417. Epub 2007/06/20. eng.

6. Koehn FE, Carter GT. The evolving role of natural products in drug discovery. Nat Rev Drug Discov. 2005 Mar;4(3):206-20. PubMed PMID: 15729362. Epub 2005/02/25. eng.

7. Jiang $\mathrm{H}, \mathrm{Wu}$ J, Zhang L, Liang W, Gao F, Du C, et al. Chemical biology in China takes on signal transduction. Nat Chem Biol. 2008 Sep;4(9):5158. PubMed PMID: 18711374. Epub 2008/08/20. eng.

8. Corson TW, Crews CM. Molecular understanding and modern application of traditional medicines: triumphs and trials. Cell. 2007 Sep 7;130(5):76974. PubMed PMID: 17803898. Pubmed Central PMCID: 2507744. Epub 2007/09/07. eng.

9. Swinney DC, Anthony J. How were new medicines discovered? Nat Rev Drug Discov. 2011 Jul;10(7):507-19. PubMed PMID: 21701501. Epub 2011/06/28. eng.

10. Munos B. Lessons from 60 years of pharmaceutical innovation. Nat Rev Drug Discov. 2009 Dec;8(12):959-68. PubMed PMID: 19949401. Epub 2009/12/02. eng.

11. Flordellis CS, Manolis AS, Paris H, Karabinis A. Rethinking target discovery in polygenic diseases. Curr Top Med Chem. 2006;6(16):1791-8. PubMed PMID: 17017957. Epub 2006/10/05. eng.

12. Williams M. Systems and integrative biology as alternative guises for pharmacology: prime time for an iPharm concept? Biochem Pharmacol. 2005 Dec 5;70(12):1707-16. PubMed PMID: 16198319. Epub 2005/10/04. eng.

13. Ong SE, Schenone M, Margolin AA, Li X, Do K, Doud MK, et al. Identifying the proteins to which small-molecule probes and drugs bind in cells. Proc Natl Acad Sci U S A. 2009 Mar 24;106(12):4617-22. PubMed PMID: 19255428. Pubmed Central PMCID: 2649954. Epub 2009/03/04. eng.

14. Turner N, Li JY, Gosby A, To SW, Cheng Z, Miyoshi $\mathrm{H}$, et al. Berberine and its more biologically available derivative, dihydroberberine, inhibit mitochondrial respiratory complex I: a mechanism for the action of berberine to activate AMP-activated protein kinase and improve insulin action. Diabetes. 2008 May;57(5):1414-8. PubMed PMID: 18285556.

15. Tan MJ, Ye JM, Turner N, Hohnen-Behrens C, Ke $\mathrm{CQ}$, Tang $\mathrm{CP}$, et al. Antidiabetic activities of triterpenoids isolated from bitter melon associated with activation of the AMPK pathway. Chem Biol. 2008 Mar;15(3):263-73. PubMed PMID: 18355726. Epub 2008/03/22. eng.

16. Qiu BY, Turner N, Li YY, Gu M, Huang MW, $\mathrm{Wu} F$, et al. High-throughput assay for modulators of mitochondrial membrane potential identifies a novel compound with beneficial effects on $\mathrm{db} / \mathrm{db}$ mice. Diabetes. 2010 Jan;59(1):256-65. PubMed PMID: 19833880. Pubmed Central PMCID: 2797930

17. Zeng XY, Zhou X, Xu J, Chan SM, Xue CL,
Molero JC, et al. Screening for the efficacy on lipid accumulation in 3T3-L1 cells is an effective tool for the identification of new anti-diabetic compounds. Biochem Pharmacol. 2012 Sep 15;84(6):830-7. PubMed PMID: 22820245. Epub 2012/07/24. eng.

18. Govers R, Coster AC, James DE. Insulin increases cell surface GLUT4 levels by dose dependently discharging GLUT4 into a cell surface recycling pathway. Mol Cell Biol. 2004 Jul;24(14):6456-66. PubMed PMID: 15226445. Pubmed Central PMCID: 434240. Epub 2004/07/01. eng.

19. Huang S, Czech MP. The GLUT4 glucose transporter. Cell Metab. 2007 Apr;5(4):237-52. PubMed PMID: 17403369. Epub 2007/04/04. eng.

20. Sridhar MG, Vinayagamoorthi R, Arul Suyambunathan V, Bobby Z, Selvaraj N. Bitter gourd (Momordica charantia) improves insulin sensitivity by increasing skeletal muscle insulinstimulated IRS-1 tyrosine phosphorylation in highfat-fed rats. Br J Nutr. 2008 Apr;99(4):806-12. PubMed PMID: 17942003. Epub 2007/10/19. eng.

21. Tsai $\mathrm{CH}$, Chen EC, Tsay HS, Huang CJ. Wild bitter gourd improves metabolic syndrome: a preliminary dietary supplementation trial. Nutr J. 2012;11:4. PubMed PMID: 22243626. Pubmed Central PMCID: 3311063. Epub 2012/01/17. eng.

22. Iseli TJ, Turner N, Zeng XY, Cooney GJ, Kraegen EW, Yao S, et al. Activation of AMPK by Bitter Melon Triterpenoids Involves CaMKKbeta. PLoS One. 2013;8(4):e62309. PubMed PMID: 23638033. Pubmed Central PMCID: 3636144.

23. Zhang Y, Li Y, Guo YW, Jiang HL, Shen X. A sesquiterpene quinone, dysidine, from the sponge Dysidea villosa, activates the insulin pathway through inhibition of PTPases. Acta pharmacologica Sinica. 2009 Mar;30(3):333-45. PubMed PMID: 19262557.

24. Li Y, Tran VH, Duke CC, Roufogalis BD. Gingerols of Zingiber officinale enhance glucose uptake by increasing cell surface GLUT4 in cultured L6 myotubes. Planta medica. 2012 Sep;78(14):1549-55. PubMed PMID: 22828920.

25. Liu F, Dallas-Yang Q, Castriota G, Fischer P, Santini F, Ferrer M, et al. Development of a novel GLUT4 translocation assay for identifying potential novel therapeutic targets for insulin sensitization. Biochem J. 2009 Mar 1;418(2):41320. PubMed PMID: 19035854.

26. Samuel VT, Petersen KF, Shulman GI. Lipidinduced insulin resistance: unravelling the mechanism. Lancet. 2010 Jun 26;375(9733):226777. PubMed PMID: 20609972. Pubmed Central PMCID: 2995547. Epub 2010/07/09. eng.

27. Zeng XY, Wang YP, Cantley J, Iseli TJ, Molero $\mathrm{JC}$, Hegarty BD, et al. Oleanolic acid reduces hyperglycemia beyond treatment period with Akt/FoxO1-induced suppression of hepatic gluconeogenesis in type-2 diabetic mice. PLoS One. 2012;7(7):e42115. PubMed PMID: 22860063. Pubmed Central PMCID: 3408432. Epub 2012/08/04. eng. 
28. Hoehn KL, Hohnen-Behrens C, Cederberg A, Wu LE, Turner N, Yuasa T, et al. IRS1-independent defects define major nodes of insulin resistance. Cell Metab. 2008 May;7(5):421-33. PubMed PMID: 18460333. Pubmed Central PMCID: 2443409. Epub 2008/05/08. eng.

29. Sampson ER, McMurray HR, Hassane DC, Newman L, Salzman P, Jordan CT, et al. Gene signature critical to cancer phenotype as a paradigm for anticancer drug discovery. Oncogene. 2012 Sep 10. PubMed PMID: 22964631. Epub 2012/09/12. Eng.

30. Jayaraman S, Patel A, Jayaraman A, Patel V, Holterman M, Prabhakar B. Transcriptome analysis of epigenetically modulated genome indicates signature genes in manifestation of type 1 diabetes and its prevention in NOD mice. PLoS One. 2013;8(1):e55074. PubMed PMID: 23383062. Pubmed Central PMCID: 3559426. Epub 2013/02/06. eng.

31. Sirota M, Dudley JT, Kim J, Chiang AP, Morgan AA, Sweet-Cordero A, et al. Discovery and preclinical validation of drug indications using compendia of public gene expression data. Sci Transl Med. 2011 Aug 17;3(96):96ra77. PubMed PMID: 21849665. Pubmed Central PMCID: 3502016. Epub 2011/08/19. eng.

32. Dudley JT, Sirota M, Shenoy M, Pai RK, Roedder $\mathrm{S}$, Chiang AP, et al. Computational repositioning of the anticonvulsant topiramate for inflammatory bowel disease. Sci Transl Med. 2011 Aug 17;3(96):96ra76. PubMed PMID: 21849664. Pubmed Central PMCID: 3479650. Epub 2011/08/19. eng.

33. Zhang A, Sun H, Wang P, Han Y, Wang X. Future perspectives of personalized medicine in traditional Chinese medicine: a systems biology approach. Complement Ther Med. 2012 FebApr;20(1-2):93-9. PubMed PMID: 22305254. Epub 2012/02/07. eng.

34. Brennan AM, Mantzoros CS. Drug Insight: the role of leptin in human physiology and pathophysiology--emerging clinical applications. Nat Clin Pract Endocrinol Metab. 2006 Jun;2(6):318-27. PubMed PMID: 16932309. Epub 2006/08/26. eng.

35. Coleman DL, Hummel KP. The influence of genetic background on the expression of the obese (Ob) gene in the mouse. Diabetologia. 1973 Aug;9(4):287-93. PubMed PMID: 4588246. Epub 1973/08/01. eng.

36. Frederich RC, Hamann A, Anderson S, Lollmann B, Lowell BB, Flier JS. Leptin levels reflect body lipid content in mice: evidence for diet-induced resistance to leptin action. Nat Med. 1995 Dec;1(12):1311-4. PubMed PMID: 7489415. Epub 1995/12/01. eng.

37. Chen G, Lai X, Jiang Q, Chen F, Chen N, Huang $\mathrm{H}$, et al. Cardiovascular disease (CVD) risk, insulin resistance and beta-cell function in prehypertension population of China. Atherosclerosis. 2011 Jul;217(1):279-85. PubMed
PMID: 21501840. Epub 2011/04/20. eng.

38. Kobayashi K, Forte TM, Taniguchi S, Ishida BY, Oka K, Chan L. The db/db mouse, a model for diabetic dyslipidemia: molecular characterization and effects of Western diet feeding. Metabolism. 2000 Jan;49(1):22-31. PubMed PMID: 10647060. Epub 2000/01/26. eng.

39. Sacca R, Engle SJ, Qin W, Stock JL, McNeish JD. Genetically engineered mouse models in drug discovery research. Methods Mol Biol. 2010;602:37-54. PubMed PMID: 20012391. Epub 2009/12/17. eng.

40. Maffei M, Stoffel M, Barone M, Moon B, Dammerman M, Ravussin E, et al. Absence of mutations in the human OB gene in obese/diabetic subjects. Diabetes. 1996 May;45(5):679-82. PubMed PMID: 8621022. Epub 1996/05/01. eng.

41. Stirling B, Cox NJ, Bell GI, Hanis CL, Spielman $\mathrm{RS}$, Concannon P. Identification of microsatellite markers near the human ob gene and linkage studies in NIDDM-affected sib pairs. Diabetes. 1995 Aug;44(8):999-1001. PubMed PMID: 7622007. Epub 1995/08/01. eng.

42. Park SY, Cho YR, Kim HJ, Higashimori T, Danton C, Lee MK, et al. Unraveling the temporal pattern of diet-induced insulin resistance in individual organs and cardiac dysfunction in C57BL/6 mice. Diabetes. 2005 Dec;54(12):353040. PubMed PMID: 16306372. Epub 2005/11/25. eng.

43. Ye JM, Iglesias MA, Watson DG, Ellis B, Wood L, Jensen PB, et al. PPARalpha /gamma ragaglitazar eliminates fatty liver and enhances insulin action in fat-fed rats in the absence of hepatomegaly. Am J Physiol Endocrinol Metab. 2003 Mar;284(3):E531-40. PubMed PMID: 12556350. Epub 2003/01/31. eng.

44. Chalkley SM, Hettiarachchi M, Chisholm DJ, Kraegen EW. Long-term high-fat feeding leads to severe insulin resistance but not diabetes in Wistar rats. Am J Physiol Endocrinol Metab. 2002 Jun;282(6):E1231-8. PubMed PMID: 12006352. Epub 2002/05/15. eng.

45. Mu J, Woods J, Zhou YP, Roy RS, Li Z, Zycband $\mathrm{E}$, et al. Chronic inhibition of dipeptidyl peptidase4 with a sitagliptin analog preserves pancreatic beta-cell mass and function in a rodent model of type 2 diabetes. Diabetes. 2006 Jun;55(6):1695704. PubMed PMID: 16731832.

46. Samuel VT, Shulman GI. Mechanisms for insulin resistance: common threads and missing links. Cell. 2012 Mar 2;148(5):852-71. PubMed PMID: 22385956. Pubmed Central PMCID: 3294420. Epub 2012/03/06. eng.

47. Savage DB, Petersen KF, Shulman GI. Disordered lipid metabolism and the pathogenesis of insulin resistance. Physiol Rev. 2007 Apr;87(2):507-20. PubMed PMID: 17429039. Epub 2007/04/13. eng.

48. Schenk S, Saberi M, Olefsky JM. Insulin sensitivity: modulation by nutrients and inflammation. J Clin Invest. 2008 Sep;118(9):2992-3002. PubMed PMID: 
18769626. Pubmed Central PMCID: 2522344. Epub 2008/09/05. eng.

49. Hoehn KL, Salmon AB, Hohnen-Behrens C, Turner N, Hoy AJ, Maghzal GJ, et al. Insulin resistance is a cellular antioxidant defense mechanism. Proc Natl Acad Sci U S A. 2009 Oct 20;106(42):17787-92. PubMed PMID: 19805130. Pubmed Central PMCID: 2764908. Epub 2009/10/07. eng.

50. Lee YS, Kim WS, Kim KH, Yoon MJ, Cho HJ, Shen Y, et al. Berberine, a natural plant product, activates AMP-activated protein kinase with beneficial metabolic effects in diabetic and insulin-resistant states. Diabetes. 2006 Aug;55(8):2256-64. PubMed PMID: 16873688. Epub 2006/07/29. eng. 